\title{
THE EFFECT OF MONOSIALOGANGLYOSIDE (GM-1) ADMINISTRATION IN SPINAL CORD INJURY
}

\author{
Tarcisio Eloy Pessoa Barros Filho ${ }^{1}$, Fernando Flores de Araujo ${ }^{1}$, lucas da Paz Higino ${ }^{1}$, \\ Raphael Martus Marcon ${ }^{2}$, alexandre Fogaça CRIstante $^{1}$
}

1. Universidade de São Paulo, Faculdade de Medicina, Department of Orthopedics and Traumatology, São Paulo, SP, Brazil 2. Universidade de São Paulo, Faculdade de Medicina, Hospital das Clínicas, Instituto de Ortopedia e Traumatologia, São Paulo, SP, Brazil

\section{ABSTRACT}

Objective: To evaluate the effect of monosialoganglioside $(\mathrm{GM}-1)$ in spinal cord trauma patients seen in our service who have not been treated with methylprednisolone. Methods: Thirty patients with acute spinal cord trauma were randomly divided into two groups. In Group 1, patients received 200 mg GM-1 in the initial assessment and thereafter received $100 \mathrm{mg}$ intravenous per day for 30 days and Group 2 (control) received saline. Patients were evaluated periodically (at 6 weeks, 6 months, one year and two years), using a standardized neurological assessment of the American Spinal Injury Association / International Spinal Cord Society. Results: The comparative statistical analysis of motor indices, sensitive indices for pain and touch according to the standardization of ASIA / ISCOS showed that the assessments at 6 weeks, 6 months and 2 years, GM-Group 1 patients had higher rates than the control group regarding sensitivity to pain and touch, with no statistically significant difference from the motor index. Conclusion: The functional assessment showed improvement in the sensitive indices of patients treated with GM1 after post-traumatic spinal cord injury compared to patients who received placebo. Level of Evidence IV, Prospective Case Studies Series.

Keywords: Spinal cord injuries. G(M1) Ganglioside. Outcome assessment (Health care).

Citation: Barros Filho TE, Araujo FF, Higino LP, Marcon RM, Cristante AF. The effect of administration of monosialoganglyoside (GM-1) In Spinal Cord Injury. Acta Ortop Bras. [online]. 2016;24(3):123-6. Available from URL: http://www.scielo.br/aob.

\section{INTRODUCTION}

The prevalence of spinal cord injury in Brazil due to external causes (accidents or violence) is high, about 71 new cases/ year/million, accounting for 11.000 new cases/year, higher than the international data, less than 50/million. The cost generated by the morbidity and mortality of spinal cord injury, taking into account only primary care hospital expenses amounts to approximately US $\$ 95.0000^{1,2}$

After a spinal cord injury, a complex process of metabolic reactions ultimately leads to cell death and consequently, functional loss. The cellular necrosis at the site of injury due to mechanical stress is followed by secondary injury of apoptotic nature, that also affects the adjacent tissue through a sequence of neurochemical changes - the "reactive cascade".,4

The primary injury, a mechanical one, is irreversible and the surgical decompression and mechanical stabilization can be applied in cases of unstable fractures with medullar injury. ${ }^{5}$ Currently, the therapeutic principle of medical treatment of spinal cord injury is directed to the reduction/inactivation of the secondary injury and to the attempt to promote axonal regeneration. Unfortunately, however, the current research efforts did not yet led to a pharmacological strategy with proven benefits, and only two drugs are used clinically: monosialoganglioside (GM-1) and methylprednisolone. ${ }^{6-8}$

One alternative that has been tested is the early administration of high doses of methylprednisolone. However, the evidences of its effectiveness are weak ${ }^{6-10}$ and the harmful effects of this substance for neuronal regeneration are already know, such as inhibition of immune cell activity, ${ }^{11}$ neutropenia, exacerbation of post-ischemic necrosis and inhibition of axonal sprouting, ${ }^{12}$ as well as respiratory complications, sepsis and gastrointestinal bleeding. ${ }^{6}$

Gangliosides are sialic acid derivatives of endogenous glycolipids present predominantly in the cell membrane in the central nervous system (CNS). GM-1 is already a therapeutic option for treatment of CNS injuries with antineurotoxic

All the authors declare that there is no potential conflict of interest referring to this article.

Work developed at Universidade de São Paulo, Faculdade de Medicina, Hospital das Clínicas, Department of Orthopedics and Traumatology, Spinal Cord Trauma Unit, São Paulo, SP, Brazil.

Correspondence: Fernando Flores de Araújo. Rua Dr. Ovídio Pires de Campos, 333. 05403-010 São Paulo, SP, Brazil. fernando.faraujo@hc.fm.usp.br 
anti-inflammatory and neuroprotective effects, being essential in neuronal excitability. ${ }^{13}$ Moreover, it promotes the development, growth, differentiation and neuronal maturation and reduces the intensity of the Waleriana degeneration. ${ }^{13,14}$ Research involving GM-1 in humans have shown improvement of locomotor function in spinal cord injury victims, ${ }^{15}$ but the interpretation of these results is complicated by the fact that methylprednisolone has been used prior to GM-1 administration. ${ }^{14,15}$

The purpose of this study was to evaluate the effect of monosialoganglioside $(\mathrm{GM}-1)$ in spinal cord trauma patients seen in our service that have not been previously treated with methylprednisolone.

\section{MATERIALS AND METHODS}

This is a controlled, double blind study aimed to compare the use of monosialoganglioside (GM-1) versus placebo in patients suffering from spinal cord injury. It was held at the Spinal Cord Trauma Unit of Instituto de Ortopedia e Traumatologia do Hospital das Clinicas da Faculdade de Medicina da Universidade de São Paulo between January 2000 and February 2001. Every institutional and ethical norms were followed. We included 30 consecutive patients aged 18-50 years old, admitted between 8 and $72 \mathrm{~h}$ after trauma, with closed injuries of the spine from $\mathrm{C} 4$ to $\mathrm{T} 10$ with associated neurological deficit classified as: A, complete injury; $\mathrm{B}$, sensitive preservation only; $\mathrm{C}$, non-functional motor preservation; D, functional motor preservation; and $\mathrm{E}$, without any deficit, according to the American Spinal Injury Association/International Spinal Cord Society (ASIA/ISCOS) standardization (Figure 1). Patients under 18 and over 50 years old, admitted within less than $8 \mathrm{~h}$ and over $72 \mathrm{~h}$ after trauma, with spinal trauma but without any neurological deficit, with open/ exposed injuries, with spinal cord injuries above $\mathrm{C} 4$ or below T10, with altered level of consciousness making impossible to assess neurological deficit in a timely manner to be included in the protocol, with neurological deficit from other causes prior to spinal cord injury were excluded from the sample.

Patients were randomized into two groups by drawing lots in sealed envelops. GM-1 group received $200 \mathrm{mg}$ medication intravenously in primary care and thereafter $100 \mathrm{mg}$ IV per day for 30 days. The control group received saline as placebo.

Patients were evaluated periodically (at 6 weeks, 6 months, one year and two years), through an ASIA/ISCOS standardized neurological assessment, consisting of sensory and motor evaluation. The first one is divided into pain (nip) and light touch (cotton). Both are ranked as (2) Normal, (1) impaired, and (0) with no sensitivity. For each type of sensitivity (superficial touch and pain) a total score of

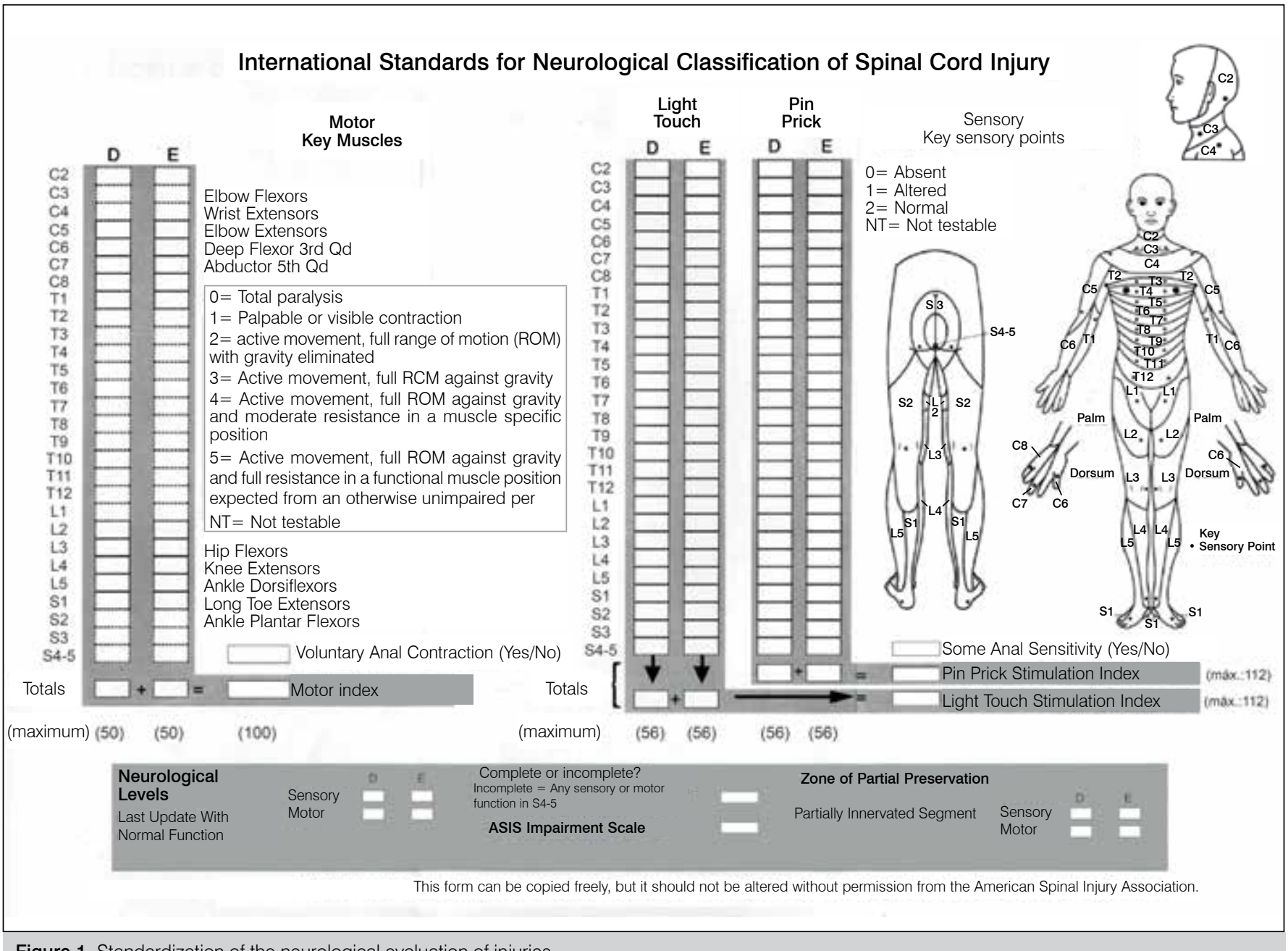

Figure 1. Standardization of the neurological evaluation of injuries 
56 points is produced ( 0 to 2 for each of the 23 defined dermatomes). The overall sensory index is 112 for each tested sensitivity. Motor evaluation is ranked $0-5$, according to the Medical Research Council Scale for Muscle Strength: (0) paralysis; (1) movements present without overcoming gravity; (2) movement in full amplitude overcoming gravity; (3) full range movements overcoming gravity, (4) against some resistance; and (5) against total resistance. If a muscle could not be tested, it was defined as NT (not tested). The sensory and motor indexes are the numerical sum of the scores, reflecting the degree of neurological disability associated with spinal cord injury.

Statistical analysis was based in mean, median and standard deviation of the data. The results were compared using mixed effect models with two factors: group and assessment week, considering the repetition of measurements over the weeks. The effect of the interaction between these factors was also evaluated. The association between the index obtained and the groups was assessed using Fisher's exact test. $p$-Values less than 0.05 were considered as statistically significant.

\section{RESULTS}

The groups were similar in terms of injury location (in the GM-1 group there were 10 cervical injuries and five thoracic injuries; in the control group there were nine cervical injuries and six thoracic injuries). The mean age was 32.1 years old in GM-1 group and 30.8 in the control group. The mean arrival time at the hospital after trauma was 24h in GM-1 group and 26h in the control group. Regarding gender, there were 14 men and one woman in both groups. Initial ASIA/ISCOS motor index was 39 in GM-1 group and 37 in the control group; as for sensitive ASIA/ISCOS pain index, it was 51 in GM-1 group and 53 in the control group; and touch sensitive index was 60 in GM-1 group and 61 in the control group.

The comparative statistical analysis of motor indexes, sensitive index for pain and sensitive index for touch, according to ASIA/ISCOS standardization, showed that in assessments at 6 weeks, 6 months and 2 years, patients in the GM-1 group showed higher rates than the control group regarding sensitivity to pain and touch, with no statistically significant difference for motor index.

\section{DISCUSSION}

Recently, research in spinal cord injury shifted its focus from attempts to stop or slow the cascade of events of the secondary injury to effectively finding drugs that promote neuronal repair and regeneration. It has been known for some time that neuronal regeneration capacity, although somewhat reduced in the central nervous system as to the peripheral nervous system, recovers slowly and incompletely. ${ }^{7,16}$ The mortality rate in the first year after the acute phase of spinal cord injury ranges from 8 to $15 \% .17,18$

Those patients have neural and morphological changes in the gastrointestinal system, obesity and its comorbidities, such as hypertension, heart disease, diabetes mellitus, decubitus ulcers, vascular disorders, tendinous muscular contractures, and sexual dysfunction. Chronic pain affects between 11 and $94 \%$ of these cases, substantially increasing the incidence of mental illness and difficulty of maintenance therapies. ${ }^{19,20}$ Although there is no consensus, GM-1 shows with to be a promising therapeutic option, evidence of its benefit both isolated or in combination with other physical, chemical or biological means have been found in the literature. Souza et al., ${ }^{21}$ although not statistically significant, demonstrated the benefit of GM-1 in rats with experimental spinal cord injury, reaching higher rank in the assessment by the BBB score.

Santos et al..$^{22}$ and Souza et al.$^{23}$ presented preliminary results favorable to low temperature laser associated to GM-1 in spinal cord and peripheral nervous system injuries, while others have failed to demonstrate statistical significance regarding neurological recovery or show any difference between the results by evaluating the evoked potential.

Hyperbaric oxygen therapy was also investigated as a GM-1 enhancer in rats with experimental spinal cord injury and, although not statistically significant, has showed benefits in neurological recovery with $\mathrm{GM}-1$, and this benefit was anticipated by hyperbaric oxygen therapy. ${ }^{24}$ Marcon, ${ }^{25}$ in his thesis, also showed that GM-1 and erythropoietin have therapeutic effects on motor and electrophysiological function and axonal regeneration in Wistar rats with experimental spinal cord injury. Moreover, this author found out that that the combination of both substances potentiates its effect.

GM-1 appears to be reliable in all cases of spinal cord injury. In our study we showed significant differences among the groups. From the sixth week after spinal cord injury, patients who received $\mathrm{GM}-1$ had a significant neurological improvement (according to ASIA/ISCOS standardization) as compared to patients who received placebo. The evidence that the performance was improved up to two years, makes one think that in acute and subacute spinal cord injuries benefit from GM-1. It would be interesting to reevaluate those benefits with a larger sample and other bone marrow analyzes, such as electron microscopy and specific methods of nerve regeneration, besides new experimental studies employing associations of growth factors and neural protectors, among other molecules, in search for more significant results in spinal cord injured patients.

\section{CONCLUSION}

Functional assessment of patients shows improvement in sensory indexes with GM1 after post-traumatic spinal cord injury as compared to patients treated with placebo.

\section{ACKNOWLEDGEMENTS}

The authors are grateful to TRB Pharma, Brazil, for the donation of monosialoganglyoside (GM-1) used in this experimental study.

AUTHORS' CONTRIBUTION: RMM (0000-0001-5958-5646)* and AFC (0000-0002-7797-5274)* performed the bibliographic search and assessed data from statistical analysis. FFA (0000-0003-4008-3667)* and LPH (0000-0002-0746-265X)* collected experimental data and followed up the patients. TEPBF (0000-0002-0819-7712)* was the main contributor in writing and reviewing the manuscript, having contributed to the intellectual concept of the study. ${ }^{*} \mathrm{ORCID}$ (Open Research and Contributor ID). 


\section{REFERENCES}

1. Sekhon LH, Fehlings MG. Epidemiology, demographics, and pathophysiology of acute spinal cord injury. Spine (Phila Pa 1976). 2001;26(24 Suppl):S2-12.

2. Masini M. Estimativa da incidência e prevalência de lesão medular no Brasil. J Bras Neurocir. 2001;12(2):97-100.

3. Ray SK, Matzelle DD, Wilford GG, Hogan EL, Banik NL. Cell death in spinal cord injury $(\mathrm{SCl})$ requires de novo protein synthesis. Calpain inhibitor E-64-d provides neuroprotection in SCl lesion and penumbra. Ann N Y Acad Sci. 2001;939:436-49.

4. Beattie MS, Farooqui AA, Bresnahan JC. Review of current evidence for apoptosis after spinal cord injury. J Neurotrauma. $2000 ; 17(10): 915-25$.

5. Fouad K, Krajacic A, Tetzlaff W. Spinal cord injury and plasticity: opportunities and challenges. Brain Res Bull. 2011;84(4-5):337-42.

6. Bracken MB, Shepard MJ, Holford TR, Leo-Summers L, Aldrich EF, Fazl M, et al. Methylprednisolone or tirilazad mesylate administration after acute spinal cord injury: 1-year follow up. Results of the third National Acute Spinal Cord Injury randomized controlled trial. J Neurosurg. 1998;89(5):699-706.

7. Gebrin AS, Cunha AS, Da-Silva CF, Barros Filho TE, Azze RJ. Perspectivas de recuperação do lesado medular. Rev Bras Ortop. 1997;32(2):103-8.

8. Gebrin AS, Cristante AF, Marcon RM, Silva CF, Barros Filho TEP. Intervenções farmacológicas no trauma raquimedular: uma nova visão terapêutica. Acta Ortop Bras. 1997;5(3):123-36.

9. Hurlbert RJ. Methylprednisolone for acute spinal cord injury: an inappropriate standard of care. J Neurosurg. 2000;93(1 Suppl):1-7.

10. Short $\mathrm{D}$. Is the role of steroids in acute spinal cord injury now resolved? Curr Opin Neurol. 2001;14(6):759-63.

11. Bracken MB, Shepard MJ, Collins WF Jr, Holford TR, Baskin DS, Eisenberg $\mathrm{HM}$, et al. Methylprednisolone or naloxone treatment after acute spinal cord injury: 1-year follow-up data. Results of the second National Acute Spinal Cord Injury Study. J Neurosurg. 1992;76(1):23-31.

12. Bracken MB, Shepard MJ, Holford TR, Leo-Summers L, Aldrich EF, Fazl M, et al. Administration of methylprednisolone for 24 or 48 hours or tirilazad mesylate for 48 hours in the treatment of acute spinal cord injury. Results of the Third National Acute Spinal Cord Injury Randomized Controlled Trial. National Acute Spinal Cord Injury Study. JAMA. 1997;277(20):1597-604

13. Geisler FH, Coleman WP, Grieco G, Poonian D. The Sygen multicenter acute spinal cord injury study. Spine (Phila Pa 1976). 2001; 26(24 Suppl):S87-98.

14. Blight AR, Zimber MP. Acute spinal cord injury: pharmacotherapy and drug development perspectives. Curr Opin Investig Drugs. 2001;2(6):801-8.

15. Cristante AF, Barros TE, Marcon RM, Letaif OB, Rocha ID. Therapeutic approaches for spinal cord injury. Clinics (Sao Paulo). 2012;67(10):1219-24.

16. Haan N, Song B. Therapeutic Application of Electric Fields in the Injured Nervous System. Adv Wound Care (New Rochelle). 2014;3(2):156-165.

17. Krause JS, Carter RE, Pickelsimer EE, Wilson D. A prospective study of health and risk of mortality after spinal cord injury. Arch Phys Med Rehabil. 2008;89(8):1482-91.

18. Banerjea R, Sambamoorthi U, Weaver F, Maney M, Pogach LM, Findley T. Risk of stroke, heart attack, and diabetes complications among veterans with spinal cord injury. Arch Phys Med Rehabil. 2008;89(8):1448-53.

19. Noonan VK, Kopec JA, Zhang H, Dvorak MF. Impact of associated conditions resulting from spinal cord injury on health status and quality of life in people with traumatic central cord syndrome. Arch Phys Med Rehabil. 2008;89(6):1074-82

20. Raichle KA, Hanley M, Jensen MP, Cardenas DD. Cognitions, coping, and social environ-ment predict adjustment to pain in spinal cord injury. J Pain. 2007;8(9):718-29.

21. Souza FI, Barros Filho TE, Cristante AF. Avaliação do emprego do GM1 após lesão medular experimental em ratos. Coluna/Columna. 2011;10(4):305-8.

22. Santos GB, Barros Filho TE, Cristante AF, Silva CF, Marcon RM, Souza FI, et al. Local application of Ganglioside GM1 with lasermed by the criopass therapy method improves peripheral nerve and spinal cord regeneration in rats. FENS (Annals). 2010;5:040,19. [Abstract 040,19]. Available from: http://fens2010,neurosciences.asso.fr/abstracts/r2/a040_19,html. [Accessed in 2012 Jun 5].

23. Souza FI, Cristante AF, Marcon RM, Ferreira R, Dos Santos GB, Barros Filho TE. Monossialogangliosídeo transdérmico com laser no tratamento de lesão medular espinal de ratos. Acta Ortop Bras. 2013;21(2):87-91.

24. Marcon RM, Cristante AF, de Barros Filho TE, de Oliveira RP, dos Santos GB. Potentializing the effects of GM1 by hyperbaric oxygen therapy in acute experimental spinal cord lesion in rats. Spinal Cord. 2010;48(11):808-13.

25. Marcon RM. Experimental study with functional and histological evaluation of the effect of $\mathrm{G}(\mathrm{M} 1)$ ganglioside and erythropoietin in blunt spinal cord lesion in rats [tese]. São Paulo: Faculdade de Medicina, Universidade de São Paulo; 2014. 